\title{
CARACTERIZAÇÃO DE SEMENTES DE CORNICHÃO (Lotus Corniculatus L.) E DESENVOLVIMENTO DE SUSPENSÕES PARA RECOBRIMENTO
}

\author{
E. R. ECHEVARRIA ${ }^{1 *}$, B. ZORZI' ${ }^{2}$, G. WESTPHALEN ${ }^{2}$, F. D. NORA ${ }^{2}$, \\ J. C. P. OLIVEIRA ${ }^{3}$ e G. S. ROSA ${ }^{2}$ \\ ${ }^{1}$ Universidade Federal do Pampa - Unipampa, Programa de Pós graduação em Engenharia \\ ${ }^{2}$ Universidade Federal do Pampa - Unipampa, Curso de Engenharia Química \\ ${ }^{3}$ Empresa Brasileira de Pesquisa Agropecuária - Embrapa Pecuária Sul \\ *e-mail: erechevarria@ hotmail.com
}

\begin{abstract}
RESUMO
A alimentação bovina atualmente consiste basicamente em pastagens de elevado teor forrageiro. Dentre as espécies de forrageiras destaca-se o cornichão (Lotus corniculatus L.), devido a sua facilidade de adaptação e sua resistência ao frio. Porém, apesar das inúmeras vantagens, as sementes de cornichão apresentam algumas dificuldades de trabalho como, por exemplo, a dormência tegumentar que impede o transporte da água e a oxigenação do embrião e a baixa área superficial que dificulta a regulagem de equipamentos para semeadura mecânica. A técnica de recobrimento pode ser aplicada para melhorar as propriedades das sementes. Portanto, o objetivo desse trabalho foi caracterizar física e fisiologicamente as sementes de cornichão a fim de conhecer suas propriedades e elaborar filmes para seu recobrimento que apresentem potencial protetor, melhorem as características físicas e que apresentem as características necessárias para atomização em futuros trabalhos de recobrimento em leito de jorro. Através dos resultados obtidos verificou-se que as sementes de cornichão apresentam conteúdo de umidade de 9,5\% (b.u.), diâmetro médio de Sauter de 1,13 mm, massa específica real de $1301,6 \mathrm{~kg} / \mathrm{m}^{3}$, massa específica aparente de $790,73 \mathrm{~kg} / \mathrm{m}^{3}$, porosidade do leito de partículas de 0,39 e índice de germinação de $53 \%$. Com relação aos testes de recobrimento, apenas a formulação 1 proporcionou diminuição do índice de germinação das sementes de cornichão.
\end{abstract}

\section{INTRODUÇÃO}

Os sistemas de produção de bovinos no Brasil tem sua alimentação baseada exclusivamente em pastagens, tendo no Rio Grande do Sul (RS) a predominância dos campos nativos de espécies estivais de elevado potencial forrageiro (SOARES, 2012).

O cornichão (Lotus corniculatus L.) é uma forrageira exótica bastante resistente ao frio, que prefere climas de temperado frio a temperado médio, resistindo bem às geadas. É uma espécie perene muito bem adaptada à maioria dos solos e regiões do RS, por essa razão é uma das leguminosas preferenciais para a região da Campanha (CARVALHO et al., 2010).

Além da fácil adaptação ao clima temperado, as sementes de cornichão apresentam um papel importante no melhoramento do campo nativo, uma vez que incrementam a quantidade, qualidade e sustentabilidade das pastagens. Entretanto, mesmo com inúmeras vantagens, apresentam problemas de estabelecimento e persistência que podem ser atribuídos à dormência tegumentar, que impede o transporte da água e as trocas gasosas, dificultando a embebição da semente e a oxigenação do embrião. Outras limitações das sementes de cornichão são a 
baixa área superficial e o pequeno tamanho, que impedem a regulação de equipamentos de semeadura mecânica (GOMES, FRANKE e LOPES, 2011; JÚNIOR, MENEGHELLO e MELO, 2004; CASTRO e CARVALHO, 1992).

O processo de recobrimento de sementes é uma das técnicas de tratamento pré-plantio mais promissoras atualmente, uma vez que concede às sementes proteção fitossanitária e contra agentes exteriores, possibilita $\mathrm{O}$ fornecimento de nutrientes, além de permitir uma semeadura de precisão em cultivos com plantio direto (FUNGUETTO, 2007). Os equipamentos mais utilizados para a operação de recobrimento são o tambor rotativo e o leito de jorro (MATHUR e EPSTEIN, 1974).

O objetivo desse trabalho foi caracterizar física e fisiologicamente as sementes de cornichão e elaborar diferentes formulações para o processo de recobrimento.

\section{MATERIAIS E MÉTODOS}

Para a realização deste trabalho foram utilizadas sementes de cornichão (Lotus corniculatus L.) (Figura 1) cv. São Gabriel cedidas pela Embrapa Pecuária Sul.

Figura 1- Sementes de cornichão.

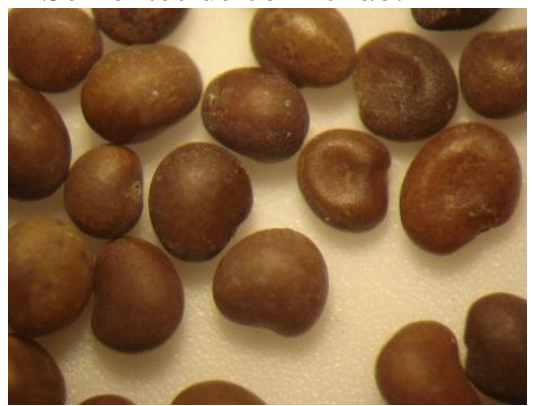

Fonte: Autor (2015).

O conteúdo de umidade das sementes foi determinado em estufa a $105{ }^{\circ} \mathrm{C}$ por um período de $24 \mathrm{~h}$, conforme Brasil (2009). A análise foi realizada em tréplicas.

A análise morfológica das sementes foi obtida utilizando um estereomicroscópio
(Motic), como mostrado na Figura 2, com magnificação de até $400 \mathrm{X}$.

Figura 2 - Estereomicroscópio.

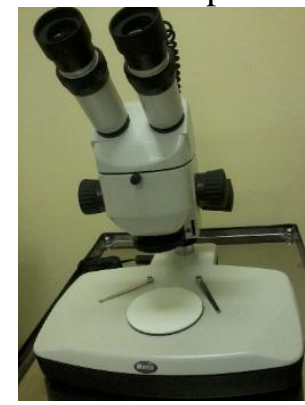

Fonte: Autor (2015).

\subsection{Caracterização Física}

A caracterização física das sementes consistiu em determinar a distribuição granulométrica, massas específicas real e aparente, porosidade do leito e classificação de acordo com diagrama de Geldart.

Análise granulométrica: foram realizados três ensaios de peneiramento utilizando um conjunto de peneiras da série Tyler (Brozinox) conforme a Figura 3.

Figura 3 - Conjunto de peneiras.

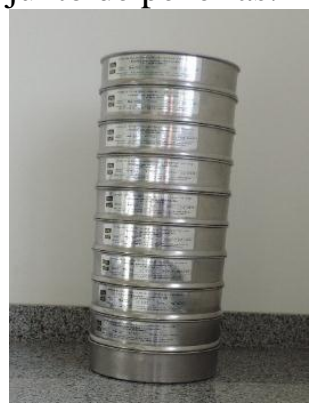

Fonte: Autor (2015).

O diâmetro médio de Sauter foi calculado através da Equação 1.

$d p_{S}=\frac{1}{\sum_{\overline{d i}}^{x i}}$

em que $x i$ é a fração mássica retida em cada peneira e $d i$ é o valor médio da abertura das peneiras passante e retida. 
Massa específica real: foram realizados ensaios através de picnometria gasosa e líquida. A picnometria gasosa foi determinada utilizando um picnômetro gasoso (Quantachrome Instruments) apresentado na Figura 4, que utiliza gás hélio.

Figura 4 - Picnômetro gasoso.

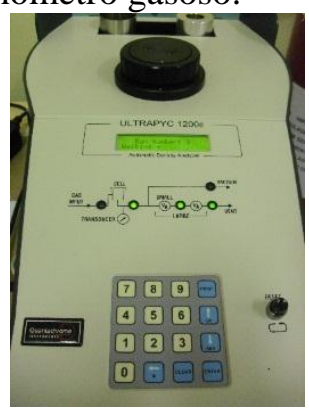

Fonte: Autor (2015).

A picnometria líquida foi realizada com picnômetro de $25 \mathrm{~mL}$ previamente calibrado. $\mathrm{O}$ procedimento foi realizado em tréplica, utilizando como solvente o hexano.

Massa específica aparente: foi determinada utilizando uma proveta de $50 \mathrm{~mL}$.

Porosidade do leito: através dos valores de massa específica real e massa específica aparente foi possível determinar, através da Equação 2, a porosidade do leito de partículas.

$\varepsilon=1-\frac{\rho_{\text {aparente }}}{\rho_{\text {real }}}$

Classificação de Geldart: utilizou-se o diagrama de Geldart para classificação de partículas sólidas, que relaciona a diferença entre massa específica do sólido e do gás $\left(\rho_{s}-\rho_{f}\right)$, com o diâmetro médio da partícula, conforme mostra a Figura 5.
Figura 5 - Diagrama de Geldart.

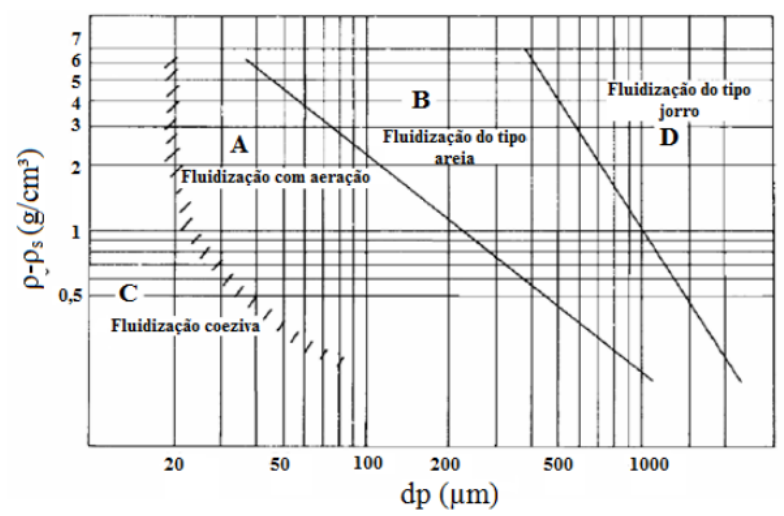

Fonte: Geldart (1986).

\subsection{Caracterização Fisiológica}

A caracterização fisiológica consistiu em determinar o índice de germinação e as curvas de embebição das sementes.

Índice de germinação: foi utilizada a metodologia recomendada em Brasil (2009). Foram utilizadas 400 sementes subdivididas em 4 repetições de 100 sementes cada. As sementes foram colocadas em caixa gerbox sobre papel de germinação umedecido com água destilada. As amostras foram levadas a estufa germinadora, operando na temperatura de $25^{\circ} \mathrm{C}$ por um período total de 12 dias.

Curvas de embebição: foram utilizadas 2000 sementes subdivididas em 4 repetições de 50 sementes. Em uma placa de petri pesou-se a massa de 50 sementes e adicionou-se $15 \mathrm{~mL}$ de água destilada deixando-as embebidas pelos períodos de $1,2,4,6,8,12,24,48,72$ e $96 \mathrm{~h}$ em estufa a $25^{\circ} \mathrm{C}$. Ao término de cada período, as sementes foram filtradas, enxutas com papel toalha e novamente pesadas.

\subsection{Recobrimento das sementes}

Para o processo de recobrimento foram elaboradas 4 diferentes formulações (Tabela 1), baseadas em trabalhos da literatura (ADEODATO, 2003; COSTA, 2010; ROSA, 2010). A motivação das formulações foi verificar através de testes preliminares o potencial de recobrimento das sementes para 
após aplicar a formulação adequada em ensaios de recobrimento em leito de jorro.

Tabela 1 - Formulações das suspensões utilizadas.

\begin{tabular}{ccccc}
\hline \multirow{2}{*}{ Componente } & \multicolumn{5}{c}{ Formulação $(\% \mathrm{p} / \mathrm{p})$} \\
& 1 & 2 & 3 & 4 \\
\hline Água & 70 & 75 & 70 & 75 \\
Talco & 5 & - & 5 & 5 \\
Terra diatomácea & 5 & 10 & 5 & - \\
Goma arábica & 5 & - & 5 & 10 \\
Amido & 5 & 5 & 5 & 5 \\
Gelatina & 5 & 5 & 5 & - \\
Colorseed & - & - & 2 & - \\
Laborsan & 2 & 2 & - & 2 \\
Glicerol & 3 & 3 & 3 & 3 \\
\hline
\end{tabular}

Fonte: Autor (2015).

Para obtenção das suspensões os reagentes utilizados em cada formulação foram pesados e colocados em um bécker, onde ficaram em agitação mecânica com rotação de $560 \mathrm{rpm}$ por $30 \mathrm{~min}$.

As suspensões foram caracterizadas com relação a concentração de sólidos através do método de estufa a $105^{\circ} \mathrm{C}$ por $24 \mathrm{~h}$.

A metodologia utilizada para o recobrimento foi baseada em trabalhos encontrados na literatura para recobrimento de sementes (AVELAR, 2009; JÚNIOR, 2008; BAYS et al., 2007). Neste sentido, foram adicionadas em um saco plástico $25 \mathrm{~g}$ de sementes, em seguida, adicionou-se $6 \mathrm{~mL}$ da suspensão, agitou-se de forma manual por 1 min até a completa distribuição do produto e cobertura das sementes e, então, levou-se para a estufa a $30{ }^{\circ} \mathrm{C}$ para secagem da película do recobrimento. Para cada formulação, realizouse o recobrimento em duplicata.

As sementes recobertas foram submetidas a análise de germinação.

\section{RESULTADOS E DISCUSSÃO}

As sementes de cornichão apresentaram conteúdo de umidade de $9,5 \pm 0,07 \%$ (b.u.). Brasil (2009) cita que sementes pequenas devem apresentar uma umidade média em torno de $12 \%$, estando portanto o valor encontrado próximo ao reportado.

Quanto a morfologia, as sementes foram caracterizadas inteiras e cortadas longitudinalmente como mostra a Figura 6.

Figura 6 - Morfologia das sementes.

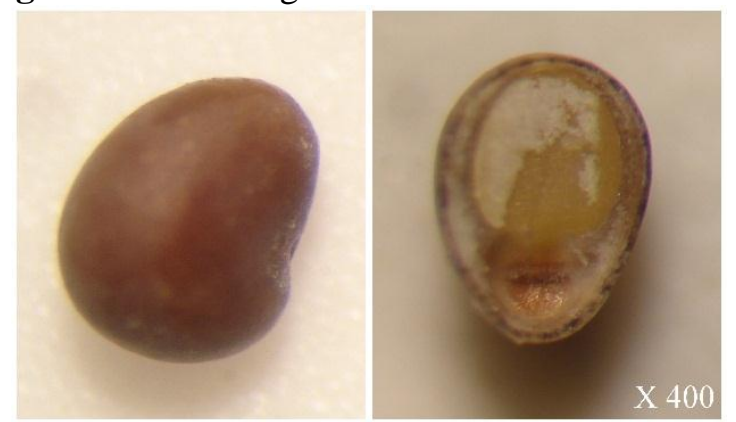

Fonte: Autor (2015).

Através da Figura 6 é possível observar a presença do embrião da semente (parte branca) e as reservas de amido (carboidrato de reserva mais comumente encontrando em sementes, parte amarela). De acordo com Lima (2005), para leguminosas, como é o caso do cornichão, o amido representa entre 30 e $40 \%$ do peso de massa seca. Também é possível observar a espessa camada de tegumento, responsável pela dormência tegumentar dessa espécie.

Através do diagrama de Geldart (1986) pôde-se classificar as sementes de cornichão como pertencentes ao grupo $\mathrm{D}$, correspondendo a fluidização do tipo jorro, demonstrando assim que estas podem ser empregadas com sucesso em processos que utilizam o leito de jorro.

A Tabela 2 apresenta os valores referentes a caracterização física das sementes. 
Tabela 2 - Valores referentes a caracterização física.

\begin{tabular}{cc}
\hline Propriedades & Valor \\
\hline$d p_{S}(\mathrm{~mm})$ & $1,13 \pm 0,0177$ \\
$\rho_{\text {real gasoso }}\left(\mathrm{kg} / \mathrm{m}^{3}\right)$ & $1301,6 \pm 0,0006$ \\
$\rho_{\text {real líquido }}\left(\mathrm{kg} / \mathrm{m}^{3}\right)$ & $1308,4 \pm 0,6442$ \\
$\rho_{\text {aparente }}\left(\mathrm{kg} / \mathrm{m}^{3}\right)$ & $790,7 \pm 0,5657$ \\
$\varepsilon$ & $0,39 \pm 0,0004$ \\
\hline
\end{tabular}

Fonte: Autor (2015).

A Figura 7 apresenta os resultados da análise granulométrica em que observam-se as curvas diferencial e acumuladas (retida e passante) para as sementes de cornichão.

Figura 7 - Distribuição granulométrica.

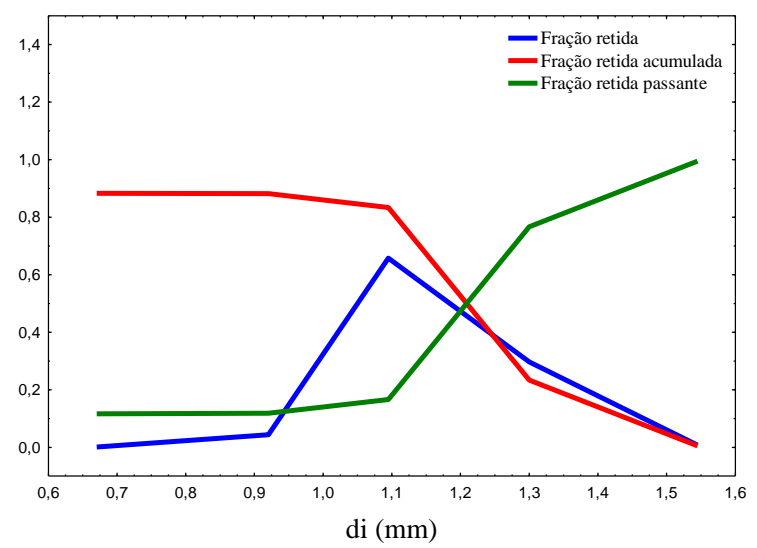

Fonte: Autor (2015).

Através da Figura 7 pode-se observar que as sementes de cornichão apresentaram um comportamento típico de distribuição granulométrica. A curva diferencial apresenta formato de curva de distribuição normal (FOUST et al., 2008).

Os valores encontrados para o conteúdo de umidade, massa específica real, massa específica aparente e porosidade do leito de partículas podem ser comparados e confirmados pelos valores encontrados por Kanaan (2014).

O resultado referente a análise de germinação das sementes de cornichão foi de $53,75 \pm 5,25 \%$, o que indica que o potencial máximo germinativo desse lote de sementes é baixo. Segundo o Padrão Nacional de
Sementes de Gramíneas e Leguminosas Forrageiras, a mínima germinação para leguminosas é de $60 \%$. A partir da amostra submetida à análise de germinação verificouse que além das sementes que germinaram, mais $15 \%$ são sementes duras (sementes com potencial germinativo porém, a dormência tegumentar impede sua embebição e assim sua germinação) e $46 \%$ são sementes mortas.

A Figura 8 apresenta a curva de embebição para sementes de cornichão que demonstra a quantidade de água absorvida por um determinado período de tempo.

Figura 8 - Curva de embebição.

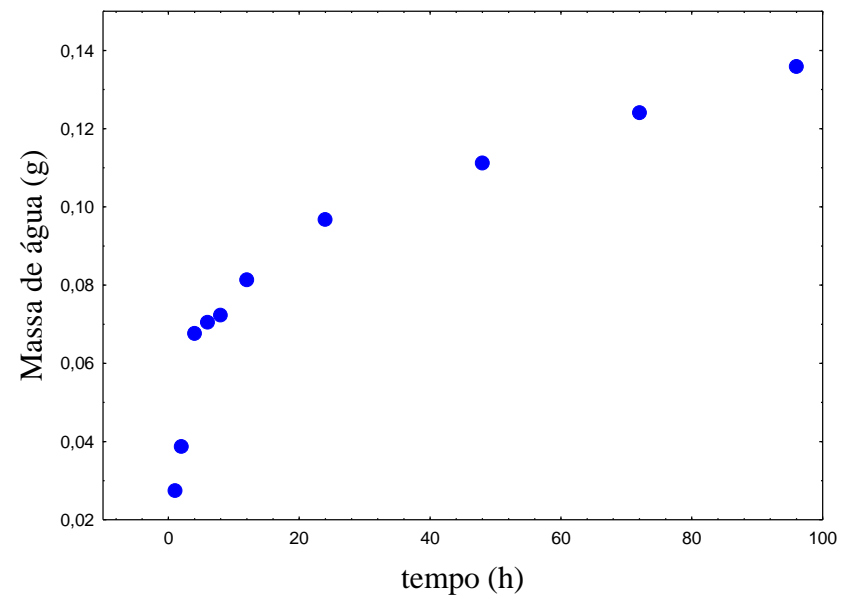

Fonte: Autor (2015).

A embebição é um processo puramente físico que depende da ligação da água à matriz da semente. A germinação segue padrão trifásico na maioria das espécies conforme mencionado por Smiderle et al., (2013). A primeira fase é a embebição propriamente dita, ocorre de forma rápida, devido à diferença de potencial de água, entre a semente e o substrato; na segunda fase ocorre uma redução na velocidade de absorção e uma série de reações químicas; na terceira fase o acréscimo de massa não se deve pela absorção de água e sim pelo início do processo germinativo das sementes. Pode-se dizer então que a curva de germinação do cornichão se enquadra no modelo trifásico assemelhando-se as curvas das oleaginosas pinhão manso (Jatropha 
curcas L.) e cártamo (Carthamus tinctorius L.) desenvolvidas por Smiderle et al. (2013) e Cunha et al. (2010).

As formulações utilizadas para $o$ recobrimento das sementes foram analisadas quanto a concentração de sólidos. A Tabela 3 apresenta os resultados obtidos.

Tabela 3 - Concentração de sólidos

\begin{tabular}{cc}
\hline Formulação & Valor \\
\hline 1 & $0,2931 \pm 0,0056$ \\
2 & $0,2149 \pm 0,0008$ \\
3 & $0,267 \pm 0,0003$ \\
4 & $0,2123 \pm 0,0039$
\end{tabular}

Fonte: Autor (2015).

O conhecimento da concentração de sólidos de uma suspensão é importante para garantir que a suspensão apresente as condições necessárias para ser atomizada.

Após recobertas as sementes foram analisadas novamente quanto ao índice de germinação, conforme exposto na Tabela 4.

Tabela 4 - Índice de germinação de sementes recobertas

\begin{tabular}{cc}
\hline Formulação & Valor \\
\hline 1 & $42 \pm 9,4692$ \\
2 & $57 \pm 9,1059$ \\
3 & $55 \pm 5,1234$ \\
4 & $60 \pm 0,5773$ \\
\hline
\end{tabular}

Fonte: Autor (2015).

É possível verificar que para as formulações 2,3 e 4 o índice de germinação aumentou quando comparado às sementes sem recobrimento. Para a formulação 1 ocorreu um decréscimo no índice de germinação.

\section{CONCLUSÕES}

Através dos resultados verificou-se que as sementes de cornichão apresentam conteúdo de umidade de $9,5 \%$ (b.u.), diâmetro médio de Sauter de $1,13 \mathrm{~mm}$, massa específica real obtida por picnometria gasosa de 1301,6 $\mathrm{kg} / \mathrm{m}^{3}$, massa específica real obtida por picnometria líquida de $1308,36 \mathrm{~kg} / \mathrm{m}^{3}$, massa específica aparente de 790,73 $\mathrm{kg} / \mathrm{m}^{3}$, porosidade do leito de partículas de 0,39 e índice de germinação de 53\%. Através da classificação de Geldart as partículas caracterizam-se por serem jorráveis (grupo D).

As curvas de germinação apresentam comportamento padrão trifásico onde pode perceber-se a fase de embebição, a de diminuição da velocidade e a fase de início do processo germinativo.

As formulações testadas para o recobrimento caracterizaram-se por possuir concentração de sólidos entre 21 e $29 \%$. A formulação 1 se comportou de maneira a diminuir o processo germinativo das sementes não sendo considerada adequada para utilização em trabalhos futuros.

Para futuros trabalhos de recobrimento de cornichão utilizando leito de jorro sugere-se utilizar como base a formulação 3 pois foi a que apresentou melhor adesão as sementes e verificar as melhorias necessárias para um perfeito recobrimento.

\section{NOMENCLATURA}

$\begin{array}{lll}\mathrm{D} & \text { Diâmetro eixo maior } & {[\mathrm{mm}]} \\ \mathrm{d} & \text { Diâmetro eixo menor } & {[\mathrm{mm}]} \\ \mathrm{d}_{\mathrm{eq}} & \text { Diâmetro equivalente } & {[\mathrm{mm}]} \\ \mathrm{d}_{\mathrm{i}} & \text { Diâmetro médio } & {[\mathrm{mm}]} \\ \mathrm{dp}_{\mathrm{s}} & \text { Diâmetro de Sauter } & {[\mathrm{mm}]} \\ \mathrm{V} & \text { Volume } & {\left[\mathrm{m}^{3}\right]} \\ \mathrm{X}_{\mathrm{i}} & \text { Fração retida } & {[-]} \\ \varepsilon & \text { Porosidade do leito } & {[-]} \\ \rho_{\text {aparente }} & \text { Massa específica aparente } & {\left[\mathrm{kg} / \mathrm{m}^{3}\right]} \\ \rho_{\mathrm{f}} & \text { Massa específica do fluido } & {\left[\mathrm{kg} / \mathrm{m}^{3}\right]} \\ \rho_{\text {real }} & \text { Massa específica real } & {\left[\mathrm{kg} / \mathrm{m}^{3}\right]} \\ \rho_{\mathrm{s}} & \text { Massa específica do sólido } & {\left[\mathrm{kg} / \mathrm{m}^{3}\right]}\end{array}$




\section{REFERÊNCIAS}

ADEODATO, M. G. Análise da fluidodinâmica de leito de jorro durante o recobrimento de partículas. Dissertação de Mestrado. Faculdade de Engenharia Química. Universidade Estadual de Campinas (UNICAMP), Campinas, 2003.

AVELAR, S. A. G. Tratamento e recobrimento de sementes de soja com polímeros líquido e em pó. Dissertação $\mathrm{DE}$ Mestrado. Programa de Pós-Graduação em Ciência e Tecnologia de Sementes. Universidade Federal de Pelotas (UFPel). Pelotas, 2009.

BAYS, R.; BAUDET, L.; HENNING, A. A.; FILHO, O. L. Recobrimento de sementes de soja com micronutrientes, fungicida e polímero. Revista Brasileira de Sementes, vol. 29, no 2, p.60-67, 2007.

BRASIL. Ministério da Agricultura, Pecuária e Abastecimento. Normas e padrões para produção e comercialização de sementes de espécies forrageiras de clima tropical. Brasília, DF, MAPA, 2008. 13 p.

BRASIL. Ministério da Agricultura, Pecuária e Abastecimento. Secretaria de Defesa Agropecuária. Regras para análise de sementes. Brasília, DF, MAPA/ACS, 2009. $399 \mathrm{p}$.

CARVALHO, P. C. F.; SANTOS, D. T.; GONÇALVES, E. N.; MORAES, A.; NABINGER, C. Forrageiras de clima temperado. Grupo de pesquisa ecologia do pastejo, cap 16. Universidade Federal do Rio Grande do Sul (UFRGS), Porto Alegre, 2010.

CAStro, C. R. T., CARvalho, W. L. Superação da dormência tegumentar em sementes de Cornichão (Lotus Corniculatus
L.). Revista da Sociedade Brasileira de Zootecnia, v.21, n. 6, p. 1009-1013, 1992.

COSTA, C. M. L. Caracterização e análise experimental do recobrimento de sementes de jambu (spilanthes oleracea) em leito fluidizado. Tese de Doutorado. Faculdade de Engenharia Química. Universidade Estadual de Campinas (UNICAMP), Campinas, 2010.

CUNHA, J. R.; RIBEIRO, L. M. P.; MELO, Y. L.; LIMA, J. P. M. S.; LICHSTON, J. E.; COSTA, M. Curva de embebição de sementes de Carthamus tinctorius $L$. In: REUNIÃO ANUAL DA SBPC, 62, 2010, Natal. Anais eletrônicos. Rio Grande do Norte: SBPC/UFRN, 2010. Disponível em: http://www.sbpcnet.org.br/livro/62ra/resumos /resumos/4704.htm.

FOUST, A. S.; WENZEL, L. A.; CLUMP, C. W.; MAUS, L.; ANDERSEN, L. B. Princípios das Operações Unitárias. Rio de Janeiro, LTC, 2008.

FUNGUETTO, C. I. Recobrimento de sementes de arroz irrigado com zinco e polímero. Norte Científico, v.2, n.1, dezembro de 2007.

GELDART, D. Gas fluidization technology. New York: John Wiley \& Sons, 1986. 468 p.

GOMES, P. S. C. F.; FRANKE, L. B.; LOPES, R. R. Florescimento e produção de sementes de Lotus subbiflorus Lag. cv. El Rincón. R. Bras. Zootec., v.40, n.5, p.964-971, 2011.

JÚNIOR, E. A. J.; MENEGHELLO, G. E.; MELO, P. T. B. S.; MAIA, M. S. Tratamentos para superação de dormência em sementes de cornichão anual. Revista Brasileira de Sementes, vol. 26, $\mathrm{n}^{\circ}$ 2, p.15-19, 2004. 
JUNIOR, J. C. B. Qualidade fisiológica de sementes de soja tratadas com fungicida $\mathrm{e}$ recobertas com polímeros. Dissertação de Mestrado. Programa de Pós-Graduação em Ciência e Tecnologia de Sementes. Universidade Federal de Pelotas (UFPel). Pelotas, 2008.

KANAAN, A.F. Análise da secagem de cornichão (Lotus Corniculatus L.) em leito fixo com escoamento de ar paralelo. Dissertação de Mestrado. Programa de PósGraduação em Engenharia. Universidade Federal do Pampa (UNIPAMPA). Bagé, 2014.

LIMA, R. V. Avaliação das características físicas e biológicas das sementes de urucu c.v. casca verde durante o desenvolvimento da maturação fisiológica. Dissertação de Mestrado. Programa de Pós-Graduação em Produção Vegetal. Universidade Federal do Espírito. Alegre, 2005.

MATHUR, K.; EPSTEIN, N. Spouted Beds, 1 ed. Academic Press Incorporated, New York, 1974.p. 304.

ROSA, G. S. Recobrimento de uréia em leito de jorro para minimizar as perdas de nitrogênio por volatilização. Dissertação de Mestrado. Faculdade de Engenharia Química. Universidade Estadual de Campinas (UNICAMP), Campinas, 2010.

SMIDERLE, O. J.; LIMA, J. M. E.; PAULINO, P. P. S. Curva de absorção de água em sementes de Jatropha curcas $L$. com dois tamanhos. Revista Agroambiente On-line, v. 7, n. 2, p. 203-208, maio-agosto, 2013.

SOARES, J. C. R. Avaliação econômica da terminação de bovinos em pastagem irrigada. Dissertação de Mestrado. Programa de Pós-Graduação em Zootecnia. Universidade
Federal do Rio Grande do Sul (UFRGS), Porto Alegre, 2012.

\section{AGRADECIMENTOS}

Ao $\mathrm{CNPq}$ pelo auxílio financeiro na realização deste trabalho;

À CAPES pela bolsa concedida;

À Unipampa pela estrutura e pelas bolsas de Iniciação Científica;

À Embrapa Pecuária Sul pelo suporte e matéria-prima cedida. 